\title{
Actualization of Electronic Health Records Affordances: An Empirical Investigation of Users' Personal and Behavioral Antecedents
}

\author{
Hamed Qahri-Saremi \\ DePaul University \\ Chicago, IL \\ hqahrisa@cdm.depaul.edu
}

\author{
Georgia Mueller-Luckey \\ Southern Illinois University \\ Edwardsville, IL \\ gmuelle@siue.edu
}

\author{
Robert Robinson \\ Southern Illinois University, \\ School of Medicine, Springfield, IL \\ rrobinson@siumed.edu
}

\author{
Rassule Hadidi \\ University of Illinois at \\ Springfield, IL \\ rhadi1@uis.edu
}

\begin{abstract}
The healthcare industry is shifting from motivating use of electronic health record (EHR) systems to promoting effective use of EHR systems as measured by patient care outcomes. This underpins the importance of understanding the process of actualizing the EHR affordances and learning how to motivate healthcare providers' use of EHR systems toward improving patient care. This study conceptualizes the process of perception and actualization of EHR affordances by drawing on the theory of affordances. We hypothesize and empirically investigate the role of user characteristics and patterns of use of EHR toward actualization of EHR affordances. To that end, we analyzed two-wave data collected from 91 healthcare professionals in an outpatient primary care clinic. Our findings support all the hypotheses. Our post-hoc analysis further shows the impact of different job roles on patterns of use of the EHR system. The theoretical and practical implications of the study are discussed.
\end{abstract}

\section{Introduction}

"...the focus will move away from rewarding providers for the use of technology and towards the outcome they achieve with their patients" [23].

This quote by the former federal administrator for the Centers for Medicare and Medicaid Services (CMS) reflects a seismic shift in the U.S. healthcare policy from motivating simply any use of healthcare information technology (HIT) to rewarding measurable improvements in patient care outcomes facilitated by HIT [23]. This underpins the urgency for developing a better understanding of HIT use within healthcare industry and learning how healthcare providers can effectively use the technology to improve patient care

\author{
Stacy Sattovia \\ Southern Illinois University, \\ School of Medicine, Springfield, IL \\ ssattovia2@siumed.edu
}

outcomes [6]. Case in point, a recent study [25] has argued that not simply use alone, but rather the perception and actualization of certain affordances within the EHR can result in effective patient outcomes.

EHR affordances refer to the potentials to achieve immediate patient care outcomes arising from the relationship between EHR and a goal-oriented user [25]. The importance of actualization of EHR affordances for the healthcare industry is indicated by the U.S. healthcare industry's delay of a $\$ 27$ billion program to incentivize EHR use [3] in order to create a program with a better focus on the identification and actualization of EHR affordances toward effective patient care outcomes. This topic is understudied in the information systems (IS) literature [2], in particular within the healthcare context. To that end, we focus on the process of identification and actualization of EHR affordances in this study.

The process of identification and actualization of EHR affordances is a function of the user, system, and goal-directed activity (a.k.a., task) [2, 25, 27]. In this study, we investigate the role of users' personal and behavioral characteristics in their interactions with the EHR in this process. Despite the arguably poignant role of users, few studies in the IS and healthcare literature have systematically investigated the role of users' characteristics in identification and actualization of EHR affordances, making it an important gap in the literature.

\section{Theory of Affordances}

Coined by Gibson [11] in a ground-breaking work in ecological psychology, an affordance is defined as what is offered, provided, or furnished to someone or something by an object. Recent IS studies have focused on the notion of affordances as a helpful lens to understand the use and effectiveness of IS [17]. 
Affordances in an IS context are described as the inherent possibilities for goal-oriented actions afforded to a user by an IS (called "technical objects" by Markus and Silver [17]). In recent years, IS researchers have made important advances in identifying and explaining affordances in the IS context and how they facilitate the effective use of the IS, including the EHR systems [e.g., 25]. This makes the affordance theory an appropriate theoretical lens for this study.

Drawing on the theory of affordances, prior research has contended that while IS have technical properties that users can make use of, these properties are merely potentials for actions and their existence alone does not guarantee effectiveness of use [21, 25]. Rather, outcomes depend on how users perceive and actualize the affordances in the context of one or more goals [21, 25]. As such, affordances are "a relational concept bridging IT artifacts and what users may do with them" [emphasis added] [17, p. 622]. Whether the users will realize and benefit from the affordances of an IS is determined by the ability of the users to perceive the affordances and then actualize the perceived affordances. As such, the process of realization of IS affordances should be discussed in terms of two main phases [2, 21, 25]: (1) perception of IS affordances, and (2) actualization of IS affordances, depicted in Figure 1.

Perception of affordances refers to opportunities for action that individuals see when they look at objects, such as "the potential for ascending provided to a person by a set of stairs" [25]. In the context of IS, perception of affordances refers to users' identification of the existence of actions possibility in an IS, which may or may not be faithful to the system designers' intentions [2]. For example, in the context of an EHR system, users' perception of an affordance can refer to whether the user is aware that the EHR can manage and track patient care orders and whether the user understands how to actualize it. Perception of an IS affordance is determined by the emergence of an affordance when a user interacts with the system and is the primary determinant of the actualization of an affordance $[2,21$, 25]. The available information about the affordances of the system along with the characteristics of the user influence how a user perceives an affordance in the system. In this study, we explain the users' characteristics that influence the perception of affordances in an EHR system. Nonetheless, perceiving system affordances is only the first step toward the effective use of the system [21], the next step is the actualization of the affordances.

Actualization of affordances entails turning perceived affordances into actions [2], which would in turn enable achieving the outcomes of the system use. Strong, et al. [25] have explained the process of actualizing the EHR affordances as an individual-level process that is experienced differently by each user taking goal-oriented actions. Individuals actualize the affordances in the system in different ways and do not necessarily experience the same steps and constraints, nor do they achieve the same outcomes [25]. As users engage with the system, users' abilities, characteristics, and preferences (e.g., their mindfulness of the system properties and their decision-making styles) as well as the work processes (tasks), policies, and environment (e.g., variations in organizational practices and norms) result in different patterns of use of the system by the users, which in turn alter the actualization of affordances by different users. The actualized affordance by a user may not necessarily correspond to the originally intended use of the system by the designer or even the user [20]. After actualizing them, the affordances lead to certain consequences, which encompass effects that are intended by the user and/or the designer as well as the unintended effects [17]. These consequences can inform the users' perceptions of the system affordances by reinforcing or adjusting their original perceptions, which in turn can lead to reinforcements or adjustments in their patterns of use of the system and actualization of its affordances [25].

In this study, we focus on the role of users' characteristics and their patterns of use of EHR, a system affordance is a relational concept between the system and the user. As such, different users' characteristics and patterns of use of the system arguably have significant influence on the actualization of affordances, making this an important addition to the current IS literature. Nonetheless, despite the central role of users in this process, with a very few exceptions

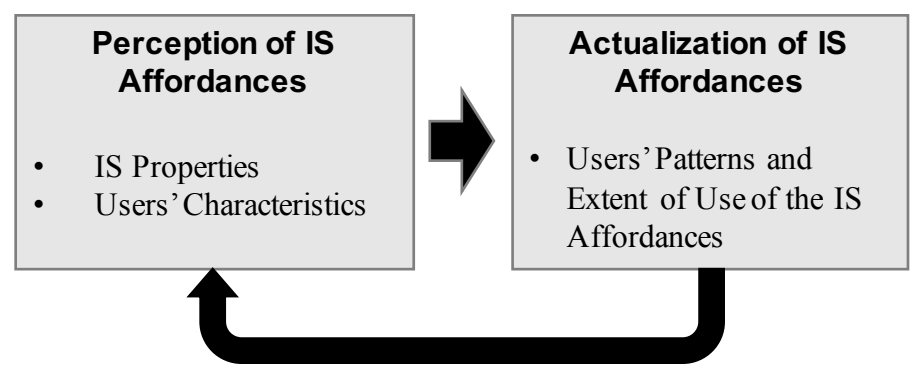

Figure 1. Conceptual Model 
[25], no study has systematically investigated this matter, making it an important gap in both affordance and EHR literatures. In particular, as depicted in Figure 2, we will explain how users' IT mindfulness, cognitive absorption, and decision styles determine their patterns of use of EHR, which in turn influence the actualization of affordances.

\section{Hypotheses Development}

Drawing on representation theory, Burton-Jones and Grange [6] explain that the core purpose of all information systems is to provide representations of the real-world systems that enable the users to better understand them. As such, the essence of any IS, including an EHR system, is the representations that are offered to the users that enable them to act in that context. For example, the task of "writing prescriptions for patients" can be represented in a paper-and-pencil format or via certain structures (functionalities) within an EHR system. These different representations of the task have different consequences for the users' (e.g., physicians') performance and the quality of care for the patients, which determine the effectiveness of using the EHR system.

In prior IS literature $[5,6]$, representations of an IS have been discussed in terms of "deep structures" within a system that can be perceived and actualized differently by different users: "deep structure conveys the meaning of a representation" [6, p. 636]. As such, the notions of representations and the deep structures provided by an IS are conceptually compatible with the notion of affordances as they all refer to the properties and structures embedded within an IS that can be perceived and actualized differently by different users [6] and may or may not be faithful to the system designers' original intention. In this study, we draw on the concept of "deep structure usage" in the context of EHR affordances identified by Strong, et al. [25] to hypothesize and measure the extent of actualization of EHR affordances by the users. We contend that actualization of system affordances can be generally manifested by two different modes: (1) routine use of the deep structures within the system and (2) innovative use of the deep structures within the system.

Routine use of the deep structures is defined as users' using the IS "in a routine and standardized way to support their work" [16, p. 662], which refers to situations where users directly leverage the existing deep structures in the IS (with no change) in support of their routine tasks. This mode of actualization of affordances is conceptually compatible with what Burton-Jones and Grange [6] explain as users' "leverage" of the existing deep structures in an IS. These deep structures are generally intended properties of the system that are designed in support of standard tasks and procedures, incorporated into users' work processes, and may be included in users' initial training and orientation for the system. Routine use of existing structures in the IS helps employees build their knowledge and skills and develop their familiarity with the deep structures within the system, thereby facilitates IS use to be better integrated in users' individual work processes [22].

Related to this discussion, Strong, et al. [25]'s case study of an EHR implementation explains that during the first two months after EHR "go-live" at a medical clinic, most providers (e.g., physicians, nurses) at the clinic "learned to routinely actualize the first two

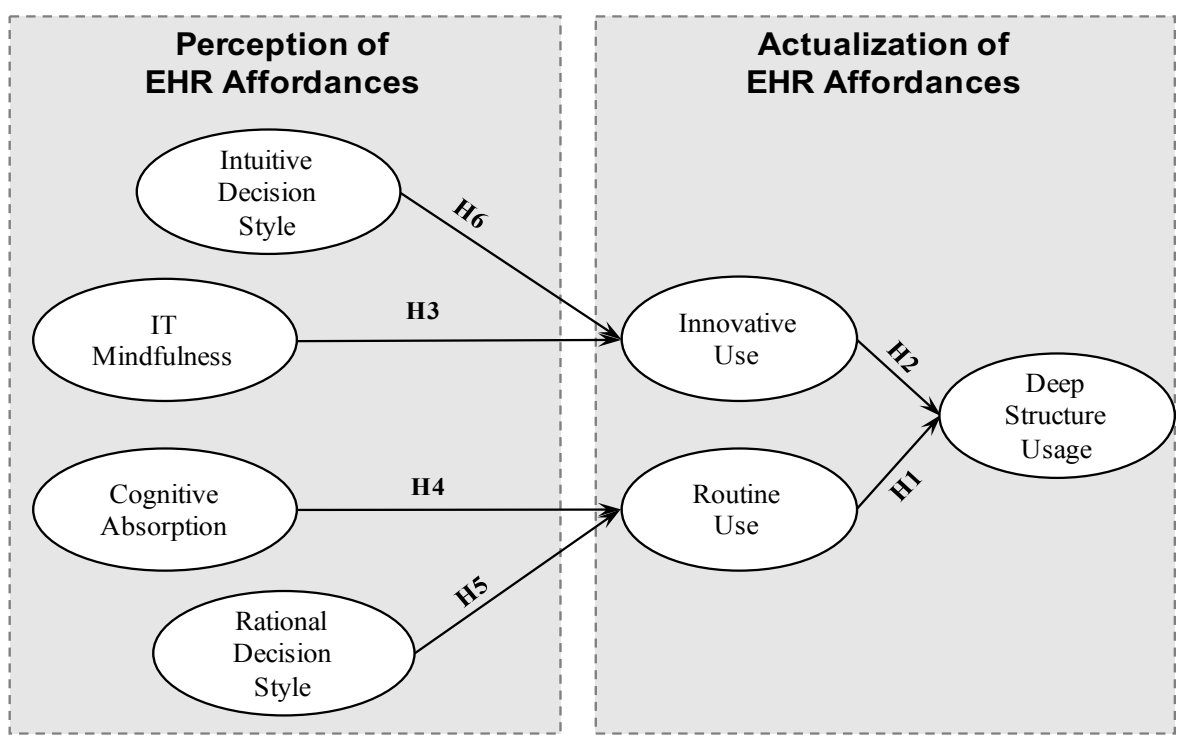

Figure 2. Our Research Model 
affordances; namely, "capturing and archiving" patientrelated data and "accessing and using" these data" [emphasis added] (p. 75), using the existing structures in the EHR. As such, we contend that routine uses of the existing deep structures within EHR is instrumental for users in understanding the deep structures within the system and actualizing them in their work processes. Therefore, routine use of EHR is expected to improve the deep structure usage of EHR. To this end, we hypothesize that:

H1: Routine uses of EHR are positively associated with deep structure usage of EHR.

Routine use of the EHR is not the only mode of actualizing its affordances. Innovative use of the EHR will also enable the users to actualize the system affordances, especially the ones that they could not actualize before, due to their lack of familiarity with the deep structures within the system [25]. Innovative use of IS is defined as users' "application of IS in novel ways to support their work" [16, p. 662]. This refers to situations where users either create or change the current structures within IS in support of tasks that may not be supported by the existing structures within IS, as perceived by the user (a.k.a., workarounds). This mode of actualization of affordances is conceptually consistent with what Burton-Jones and Grange [6] explain as "creation" and "change" of the deep structures.

In the context of database systems, Burton-Jones and Grange [6] state that many users within organizations create new spreadsheets to record data and run functions that are not supported by the current database system. They add that in such cases, users often define the meaning of data and the structure (e.g., columns and fields) in those sheets themselves and thereby create a new deep structure in support of the tasks that they would need to do using the system. Furthermore, Burton-Jones and Grange [6] draw on Boudreau and Robey [4] example of an enterprise resource planning (ERP) system where users utilize existing fields within ERP to capture information of different nature that could not be captured using the existing fields. In doing so, users alter the meaning of data and the purpose of the original fields, thereby change the existing deep structure in support of the tasks that they would need the system to facilitate. We contend that both of these cases are examples of innovative uses of the IS that enable the users to actualize affordances of the system (which may not even be, at least directly, intended by the designers).

In the EHR context, Strong, et al. [25] explain that "actualizing more basic affordances can build their [users'] knowledge and skills in ways that enable them to recognize and actualize affordances they could not before. Such learning enables actors to see innovative ways to use the technology features (i.e., to recognize previously unrecognized affordances)" (p. 76). Based on these arguments, we contend that users' innovative use of the EHR facilitates changing to or creation of new deep structures within EHR that enhance use of the EHR in support of their work. As such, we hypothesize that:

H2: Innovative uses of EHR are positively associated with deep structure usage of EHR.

Innovative and routine uses represent different modes of actualizing affordances within an EHR [25]. As explained earlier, actualization of affordances depends on the users' perceptions of the affordances (see Figure 1). One of the poignant factors that influence users' perceptions of affordances is the users' characteristics. In particular, prior IS and psychological research $[12,26]$ has shown that users' differences in their cognitive states, personality traits, and decision making styles can give rise to different modes of IS use. In particular, recent IS research [26] has differentiated between two particular users' characteristics, namely IT mindfulness and cognitive absorption.

IT mindfulness is defined as "a dynamic IT-specific trait, evident when working with IT, whereby the user focuses on the present, pays attention to detail, exhibits a willingness to consider other uses, and expresses genuine interest in investigating IT features and failures" [26, p. 5]. IT mindfulness in the EHR context refers to an overarching mindset driven by individual awareness of the context of the work at hand, and openness to value-adding (perhaps novel) applications of EHR structures in support of the work [26]. Since mindfulness compels active rather than passive thinking by nature [26], IT mindfulness has been conceptually linked to more active, innovative IS use than more automatic, routine IS use [26]. Users who are more IT mindful do not restrict themselves to standard, existing structures within a system. They are likely to scan the different possibilities for actions (i.e., affordances) within the system, and if needed, change the existing structures or create new structures in the system in support of a given task $[15,26]$.

Unlike IT mindfulness, which constitutes a broad perspective expanding beyond the existing system structures and compelling innovative use of the system, cognitive absorption refers to a cognitive state of immersion in the moment that is narrowly focused on using the existing structures of the system in support of the work at hand [26]. As such, IT mindfulness and cognitive absorption differ in terms of their task focus, which is the target of a user's attention when completing a task [9]. IT mindfulness necessitates a broad task focus on using, adapting, or creating structures within an IS to support different aspects of users' job. In contrast, cognitive absorption entails a narrow focus on 
completing a specific task using existing structures within the IS. An IT mindful user would likely be aware of how new deep structures within an IS enable completion of new tasks. In contrast, cognitively absorbed users focus on only performing a narrowly defined set of tasks, using a narrowly defined set of existing structures to accomplish a desired outcome [26]. To this end, we argue that IT mindful users are more likely to identify a greater number of opportunities for innovative IS use, while cognitively absorbed users are more likely to master and routinely use the existing structures within the IS in support of their current tasks. Therefore, we hypothesize:

H3: Users' IT mindfulness is positively associated with their innovative use of EHR.

H4: Users' Cognitive Absorption is positively associated with their routine use of EHR.

Recent research on personality has shown that individuals can have different decision styles that influence their likelihood of engaging in different behaviors [12]. Decision styles are defined as likelihoods of behavior that determine the action in response to factors such as decision time, task familiarity, information need, and environmental pressure. Recent research on individuals' decision styles [12] have identified two distinct styles of decisionmaking among individuals with significant implications on their behaviors: (1) rational decision style and (2) intuitive decision style. Rational decision style is characterized by a systematic search and processing of available information in support of a task at hand, whereas an intuitive decision style is characterized by the use of a heuristic-based and intuitive process primarily based on gut feelings, intuitions, and experience [12]. As such, rational decision style entails a systematic, rule-governed, and structured reasoning, while intuitive decision style involves a heuristic, experiential, and less structured approach to decisionmaking [12].

We argue that routine use of an IS, which requires the user to master and systematically use the existing deep structures within the IS, as often intended by the system designers, is more conducive to users with rational decision style. The reason is that existing structures within an IS are typically established and designed based on the work processes that allow for rational decision making approaches to task completion. In contrast, we argue that intuitive decision style is more conducive to innovative use of an IS. This is because innovative use requires users' reliance on heuristics, and "out-of-box" thinking to develop ideas that allow them to create or change the deep structures within IS in support of their work. As a result, we propose the following hypotheses:

H5: Users' rational decision style is positively associated with their routine use of EHR.

H6: Users' intuitive decision style is positively associated with their innovative use of EHR.

\section{Methods}

\subsection{Procedure and Sample}

To test our hypotheses, we collected cross-sectional, self-report data using online survey from EHR users in an outpatient settings in a large primary care clinic at a medical school (270 physicians, 425,000 outpatient visits per year) in the Midwestern region of the United States. The physicians and other healthcare providers participating in this survey were employed by the medical school. Most physicians at this location were practicing exclusively in this outpatient site and were considered full-time. The data were successfully collected in two rounds $\left(t_{1}\right.$ and $\left.t_{2}\right)$ from 91 respondents, with two weeks in between, to reduce the possible effect of common method bias. The respondents included physicians and resident physicians (35\%), medical students (31\%), and nurses and certified medical assistants (CMA) (34\%), who had worked with the EHR system in the outpatient setting within the medical clinic for at least 6 months. The respondents included $66 \%$ female and $34 \%$ male, with median age range of 31 to 35 years old. On the average, they had more than 5 years of EHR experience.

\subsection{Measures}

Measurement items were adapted from wellestablished and validated research instruments to the context of EHR (see Appendix A). The items were measured using a seven-point Likert scale. Specifically, Deep Structure Usage was measured at $\mathrm{t}_{2}$ adapted from Thatcher, et al. [26]. We drew on the eight EHR affordances identified by Strong, et al. [25] to measure the extent of use of the EHR affordances. Innovative Use and Routine Use were measured at $\mathrm{t}_{2}$ adapted from $\mathrm{Li}$, et al. [16]. IT Mindfulness was measured at $\mathrm{t}_{1}$ as a second-order reflective construct based on four firstorder constructs, adapted from Thatcher, et al. [26]. Cognitive Absorption was measured at $\mathrm{t}_{1}$ adapted from Burton-Jones and Straub [5]. Finally, Intuitive and Rational Decision Styles were measured at $\mathrm{t}_{1}$, using Hamilton, et al. [12]. 


\section{Data analysis and results}

\subsection{Preliminary analyses}

A series of preliminary data analyses were performed to ensure the absence of four artifacts that could compromise the quality of analyses: (1) low reliability of constructs [19], (2) low validity of constructs [24], (3) serious deviations from normality assumption [18], and (4) multicollinearity among the constructs [18], as outlined in Table 1 .

The results of these preliminary analyses demonstrated that all factors were internally consistent with Fornell and Larcker [10]'s composite reliability scores above 0.86 [19]. They also demonstrated good construct validity with square root of average variance extracted (AVE) scores over 0.70, exceeding the corresponding correlations with other factors [24]. Furthermore, the kurtosis and skewness indices were between \pm 3 , which does not indicate any serious deviation from normality $[13,18]$. Moreover, absence of any strong correlation among factors $(>0.70)$ indicated that multicollinearity is not a concern in these data [18].

\subsection{Hypotheses Testing}

We drew on partial least square (PLS) technique for testing our proposed research model, mainly due to our relatively small sample size (91), for which PLS has been shown to be a more reliable technique, as compared to covariance-based structural equation modeling (CBSEM) technique [8]. The results of our PLS analyses show that all the hypotheses are supported (Figure 2).

As expected, deep structure usage is facilitated via routine use $(\mathrm{H} 1: 0.21, \mathrm{p}<0.05)$ and innovative use $(\mathrm{H} 2$ : $0.49, \mathrm{p}<0.001$ ) of the EHR, supporting $\mathrm{H} 1$ and $\mathrm{H} 2$. Moreover, the innovative use of the EHR is positively associated with the level of user's IT mindfulness (H3: $0.49, \mathrm{p}<0.001)$ and their intuitive decision style (H6: $0.27, \mathrm{p}<0.001$ ), supporting H3 and H6. Furthermore, as expected, the routine use of the EHR is positively associated with level of user's cognitive absorption with the EHR system $(\mathrm{H} 4: 0.24, \mathrm{p}<0.001)$ and their rational decision style (H5: 0.23, p $<0.05$ ), supporting $\mathrm{H} 4$ and H5. Together, our model respectively explained $31 \%$, $41 \%$, and $38 \%$ of the variance in users' routine use, innovative use, and deep structure usage of the EHR. In our analyses, we controlled for the effects of age, gender, EHR experience, and the user's job in the medical clinic (i.e., job role).

\subsection{Post-hoc Analysis: The Effect of Job Roles on Patterns of Use of EHR}

Considering that the EHR is an organizational IS with the objective of facilitating and supporting the work of a medical practice, patterns of EHR use can be different depending on the work practices required by users' job roles within the medical clinic. For example, the patterns of EHR use for physicians might be

Table 1. Descriptive statistics, correlations, and validity information

\begin{tabular}{|c|c|c|c|c|c|c|c|c|c|c|c|c|c|}
\hline & $\begin{array}{l}\text { Mean } \\
\text { (SD) }\end{array}$ & CR & $\begin{array}{c}\text { Sk. } \\
\text { (Kr.) }\end{array}$ & 1 & 2 & 3 & 4 & 5 & 6 & 7 & 8 & 9 & 10 \\
\hline $\begin{array}{l}\text { (1) Deep Structure Usage } \\
\left(t_{2}\right)\end{array}$ & $\begin{array}{c}4.65 \\
(1.06)\end{array}$ & 0.90 & $\begin{array}{l}-0.65 \\
(0.78)\end{array}$ & 0.71 & & & & & & & & & \\
\hline (2) Innovative Use ( $\left.t_{2}\right)$ & $\begin{array}{c}4.3 \\
(1.33)\end{array}$ & 0.93 & $\begin{array}{c}-0.29 \\
(-0.45)\end{array}$ & 0.53 & 0.85 & & & & & & & & \\
\hline (3) Routine Use $\left(t_{2}\right)$ & $\begin{array}{c}5.92 \\
(0.99) \\
\end{array}$ & 0.97 & $\begin{array}{l}-1.58 \\
(1.93)\end{array}$ & 0.34 & 0.29 & 0.95 & & & & & & & \\
\hline $\begin{array}{l}\text { (4) IT Mindfulness: } \\
\text { Alertness to Distinction } \\
\left(t_{1}\right)\end{array}$ & $\begin{array}{l}3.58 \\
(1.5)\end{array}$ & 0.96 & $\begin{array}{c}0.36 \\
(-0.53)\end{array}$ & 0.32 & 0.57 & 0.03 & 0.94 & & & & & & \\
\hline $\begin{array}{l}\text { (5) IT Mindfulness: } \\
\text { Awareness of Multiple } \\
\text { Perspectives }\left(t_{1}\right)\end{array}$ & $\begin{array}{c}5.61 \\
(1.12)\end{array}$ & 0.95 & $\begin{array}{l}-1.54 \\
(2.18)\end{array}$ & 0.12 & 0.19 & 0.09 & 0.28 & 0.95 & & & & & \\
\hline $\begin{array}{l}\text { (6) IT Mindfulness: } \\
\text { Openness to Novelty }\left(t_{1}\right)\end{array}$ & $\begin{array}{c}4.7 \\
(1.49)\end{array}$ & 0.96 & $\begin{array}{c}-0.48 \\
(-0.54) \\
\end{array}$ & 0.33 & 0.41 & 0.23 & 0.55 & 0.54 & 0.94 & & & & \\
\hline $\begin{array}{l}\text { (7) IT Mindfulness: } \\
\text { Orientation in the Present } \\
\left(t_{1}\right)\end{array}$ & $\begin{array}{c}4.92 \\
(1.24)\end{array}$ & 0.87 & $\begin{array}{l}-0.76 \\
(0.42)\end{array}$ & 0.34 & 0.42 & 0.31 & 0.48 & 0.62 & 0.56 & 0.83 & & & \\
\hline $\begin{array}{l}\text { (8) Cognitive Absorption } \\
\left(t_{1}\right)\end{array}$ & $\begin{array}{c}4.53 \\
(1.19)\end{array}$ & 0.93 & $\begin{array}{c}0.14 \\
(-0.72)\end{array}$ & 0.34 & 0.30 & 0.27 & 0.25 & 0.10 & 0.03 & 0.20 & 0.87 & & \\
\hline $\begin{array}{l}\text { (9) Intuitive Decision Style } \\
\left(t_{1}\right)\end{array}$ & $\begin{array}{c}0.16 \\
(1.06)\end{array}$ & 0.90 & $\begin{array}{c}0.52 \\
(2.54)\end{array}$ & 0.12 & 0.36 & 0.13 & 0.22 & 0.04 & 0.18 & 0.07 & 0.01 & 0.83 & \\
\hline $\begin{array}{l}\text { (10) Rational Decision } \\
\text { Style }\left(t_{1}\right)\end{array}$ & $\begin{array}{c}0.16 \\
(1.01)\end{array}$ & 0.92 & $\begin{array}{l}-0.28 \\
(2.87)\end{array}$ & 0.15 & 0.06 & 0.22 & 0.02 & 0.28 & 0.04 & 0.17 & 0.06 & -0.2 & 0.86 \\
\hline
\end{tabular}




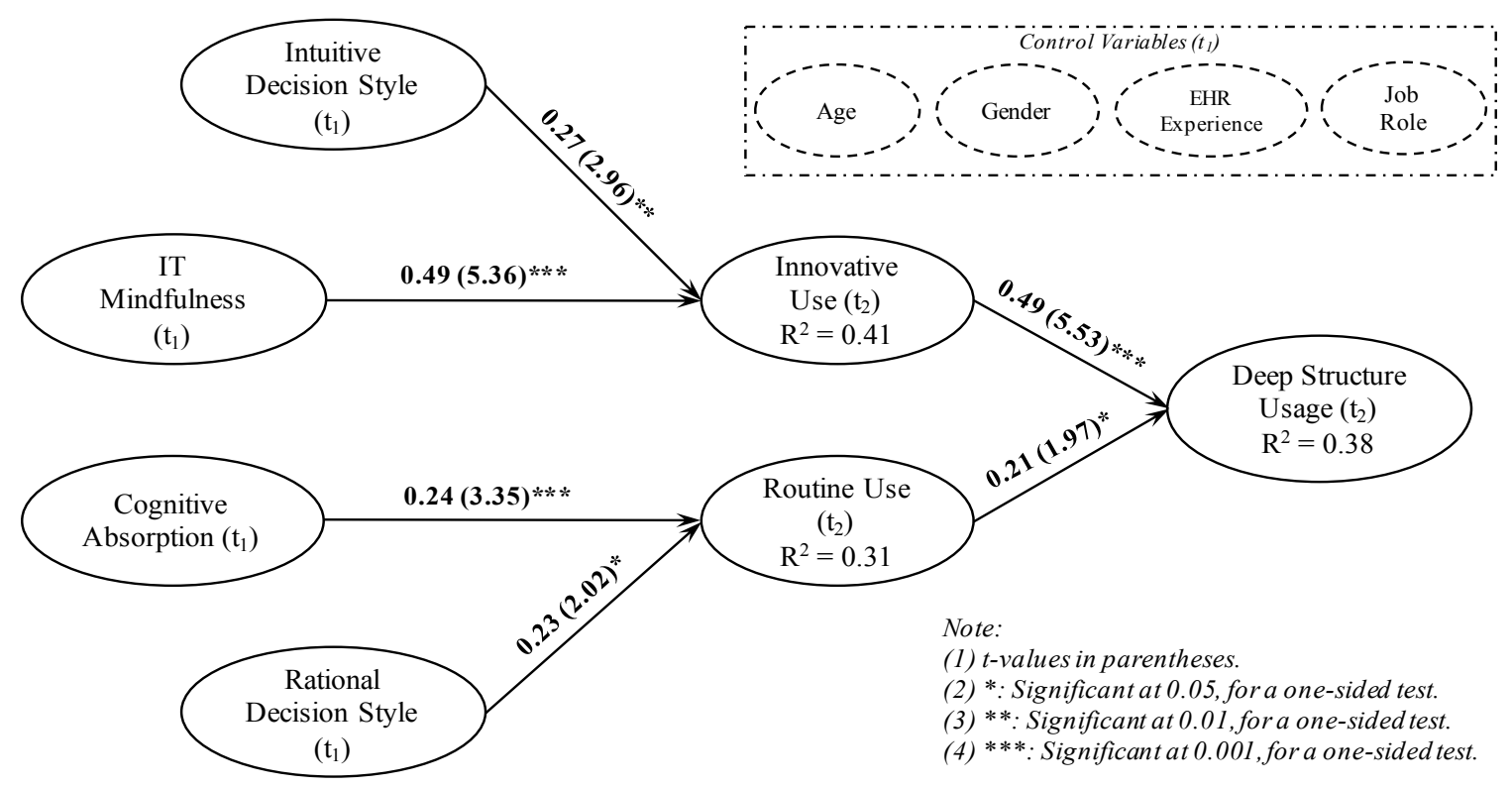

Figure 3. Results of PLS Analysis

different from those of nurses. In fact, recent studies [e.g., 14] have shown that differences in work practices influence the patterns of use of EHR. While we controlled for the possible effects of our respondents' different job roles in our PLS analysis, it would be enlightening to gain a better understanding of its effects on the users' patterns of EHR use, which is the focus of this post-hoc analysis.

We conducted a series of analyses of covariance (ANCOVA) tests to investigate whether different job roles, namely (1) physicians/residents, (2) medical students, and (3) nurses and CMAs, could significantly explain the variance in deep structure usage, innovative use, and routine use of EHR. We controlled for the effects of age, gender, and EHR experience in these analyses.

As shown in Table 2, results of ANCOVA tests show that innovative use of EHR is the only pattern of use that significantly varies across different job roles. In particular, the extent of innovative use is significantly higher among nurses and CMAs, as compared to other two groups, namely physicians/residents and medical students. However, there is no significant difference between physicians/residents and medical students regarding their innovative use of the EHR. Furthermore, our results show that there is no significant difference across job roles in terms of their routine use and deep structure usage of EHR. As such, despite the fact that nurses and CMAs use the EHR in more innovative manner, this difference is not transferred to their deep structure usage of EHR. We will discuss the implications of these findings next.

\section{Discussions}

This study sheds some light on the role of users' characteristics and patterns of use on the perception and actualization of EHR affordances. Perception and actualization of EHR affordances are an under-studied, yet important research agenda. Practitioners and regulators have been recently grappling with these affordances. Our study makes important contributions to both research and practice as follows.

\subsection{Contributions to Research}

First, this study contributes to the research on EHR affordances by conceptualizing the process through which users can identify and actualize the deep structures within EHR. This study sheds light on the role of users' traits, cognitive states, and patterns of use toward identifying and actualizing the EHR affordances.

Second, this study contributes to the IS use and affordances literature by being the first study that empirically shows the importance of the role of users' decision styles, namely intuitive and rational decision styles, on their patterns of use of IS use. Because using the deep structures within an IS, such as an EHR, requires that users make decisions about what structures within the system to use and decisions about how do to so, their decision style represents a salient characteristic in determining patterns of system use. The different patterns of use in turn can influence users' actualization of affordances of the system. In particular, our findings show that rational decision style corresponds with 
routine use of the system, and intuitive decision style is associated with the innovative use of the system.

Third, our study corroborates Thatcher, et al. [26]'s conclusion by differentiating between IT mindfulness and cognitive absorption and their corresponding patterns of use of the IS. Our findings show that while IT mindfulness is associated with innovative use of the EHR, cognitive absorption is significantly associated with routine use of the EHR. Both IT mindfulness and cognitive absorption seem amenable to change through training $[1,26]$. One implication of this is that users' pattern of use and their extent of deep structure usage of IS can be altered by training. These implications should be more thoroughly investigated in the future research.

Fourth, our post-hoc analysis sheds some light on the difference between job roles in terms of their pattern of use of the EHR and its effect on their overall usage of the EHR deep structures. Our findings show that innovative use of the EHR is significantly higher among nurses and CMAs, as compared to physicians/residents and medical students. However, there is no significant difference across job roles in terms of their routine use and deep structure usage of the EHR. In other words, while nurses and CMAs use EHR in more innovative manner, this difference is not translated to more deep structure usage of EHR. To this end, we contend that the existing deep structures within EHR may not be in line with the work processes followed by nurses and CMAs. Therefore, nurses and CMAs need to be more innovative by creating and/or changing the existing EHR structures in support of their work. The findings show that, apparently, the existing structures within EHR are more in line with the work processes followed by physicians/residents and medical students, therefore their routine use of the system is sufficient for them to benefit from its deep structures in support of their work.
An alternative reason for these findings might lie within the extent of trainings provided to physicians/residents versus nurses and CMAs and their level of familiarity with the EHR features in support of their work. This may be due to the fact that the lack of proper training and understanding of the system functionalities in support of their work might cause users to "deviate" from the standardized uses of the system and get innovative with the system. As such, these findings and contentions should be more thoroughly, and at a wider scale, studied in the future research.

\subsection{Contributions to Practice}

Our study also makes important contributions to practice. First, our findings indicate the importance of users' different patterns of use of the EHR in actualizing its affordances. Furthermore, our findings also link these patterns of use to users' personal traits, cognitive state, and decision styles. This would mean that different users with different characteristics may choose to be more or less innovative in using the EHR in support of their work, which will lead to different degrees of system "improvisations." While some levels of system improvisation are helpful in actualizing its affordances in support of the work, too much improvisation of the system may be harmful to the main objectives of the system. The same principle is applicable for the routinization and standardization of the system use: "too much standardization or too much improvisation could bring the organization to a halt" [7, p. 1098]. Therefore, finding a right balance between standardization and improvisation in the EHR is something that the system designers along with the managers should focus on. Our findings show that users' traits and decision styles are important factors for consideration in this regard.

Table 2. Results of Post-hoc ANCOVA tests

\begin{tabular}{|c|c|c|c|c|c|}
\hline Pattern of Use & Job Role (I) & Job Role (J) & Mean Difference (I-J) & Std. Error & P-Value \\
\hline \multirow{6}{*}{$\begin{array}{l}\text { Deep Structure Usage } \\
(\mathrm{t} 2)\end{array}$} & \multirow{2}{*}{$\begin{array}{l}\text { Nurse \& } \\
\text { CMA }\end{array}$} & Medical Students & 0.33 & 0.33 & 0.325 \\
\hline & & Physicians \& Residents & 0.43 & 0.30 & 0.155 \\
\hline & \multirow{2}{*}{$\begin{array}{l}\text { Medical } \\
\text { Students }\end{array}$} & Nurse \& CMA & -0.33 & 0.33 & 0.325 \\
\hline & & Physicians \& Residents & 0.11 & 0.32 & 0.739 \\
\hline & \multirow{2}{*}{$\begin{array}{l}\text { Physicians \& } \\
\text { Residents }\end{array}$} & Nurse \& CMA & -0.43 & 0.30 & 0.155 \\
\hline & & Medical Students & -0.11 & 0.32 & 0.739 \\
\hline \multirow[t]{6}{*}{ Innovative Use (t2) } & \multirow{2}{*}{$\begin{array}{l}\text { Nurse \& } \\
\text { CMA }\end{array}$} & Medical Students & 1.43 & 0.40 & 0.001 \\
\hline & & Physicians \& Residents & 0.82 & 0.36 & 0.027 \\
\hline & \multirow{2}{*}{$\begin{array}{l}\text { Medical } \\
\text { Students }\end{array}$} & Nurse \& CMA & -1.43 & 0.40 & 0.001 \\
\hline & & Physicians \& Residents & -0.61 & 0.38 & 0.116 \\
\hline & \multirow{2}{*}{$\begin{array}{l}\text { Physicians \& } \\
\text { Residents }\end{array}$} & Nurse \& CMA & -0.82 & 0.36 & 0.027 \\
\hline & & Medical Students & 0.61 & 0.38 & 0.116 \\
\hline \multirow[t]{6}{*}{ Routine Use (t2) } & \multirow{2}{*}{$\begin{array}{l}\text { Nurse \& } \\
\text { CMA }\end{array}$} & Medical Students & 0.22 & 0.29 & 0.443 \\
\hline & & Physicians \& Residents & 0.11 & 0.26 & 0.684 \\
\hline & \multirow{2}{*}{$\begin{array}{l}\text { Medical } \\
\text { Students }\end{array}$} & Nurse \& CMA & -0.22 & 0.29 & 0.443 \\
\hline & & Physicians \& Residents & -0.11 & 0.27 & 0.678 \\
\hline & \multirow{2}{*}{$\begin{array}{l}\text { Physicians \& } \\
\text { Residents }\end{array}$} & Nurse \& CMA & -0.11 & 0.26 & 0.684 \\
\hline & & Medical Students & 0.11 & 0.27 & 0.678 \\
\hline
\end{tabular}


Second, our findings indicate the significant difference across job roles in their degree of innovative use of the EHR, with nurses and CMAs being the most innovative users. As noted above, one implication of this finding can be that the existing structures within the EHR and/or the EHR trainings provided to nurses and CMAs may not be properly in line with their work practices and job needs. This presents an important area of consideration for both the EHR designers as well as the managers. Alternatively, compliance with taskspecific legal and regulatory requirements or workflow issues for physicians may suppress innovation while using the EHR.

\section{References}

[1] R. Agarwal and E. Karahanna, "Time flies when you're having fun: Cognitive absorption and beliefs about information technology usage", MIS Quarterly (2000), pp. 665-694.

[2] E. Bernhard, J. C. Recker and A. Burton-Jones, Understanding the actualization of affordances: A study in the process modeling context, International Conference on Information Systems (ICIS), Association for Information Systems (AIS), Milan, Italy, 2013.

[3] D. Blumenthal and M. Tavenner, "The "meaningful use" regulation for electronic health records", New England Journal of Medicine, 363 (2010), pp. 501-504.

[4] M.-C. Boudreau and D. Robey, "Enacting integrated information technology: A human agency perspective", Organization science, 16 (2005), pp. 3-18.

[5] A. Burton-Jones and D. W. Straub, "Reconceptualizing system usage: An approach and empirical test", Information Systems Research, 17 (2006), pp. 228-246.

[6] A. Burton-Jones and C. Grange, "From use to effective use: a representation theory perspective", Information Systems Research, 24 (2013), pp. 632-658.

[7] J. L. Carlo, K. Lyytinen and R. J. Boland Jr, "Dialectics of collective minding: contradictory appropriations of information technology in a high-risk project", MIS Quarterly, 36 (2012), pp. 1081-1108.

[8] W. W. Chin, "Issues and opinion on structural equation modeling", MIS Quarterly, 22 (1998), pp. 7-16.

[9] E. Dane, "Paying attention to mindfulness and its effects on task performance in the workplace", Journal of Management, 37 (2011), pp. 997-1018.

[10] C. Fornell and D. F. Larcker, "Evaluating structural equation models with unobservable variables and measurement error", Journal of marketing research, 18 (1981), pp. 39-50

[11] J. J. Gibson, The ecological approach to visual perception, Lawrence Erlbaum Associates, Hillsdale, NJ, 1986.

[12] K. Hamilton, S.-I. Shih and S. Mohammed, "The Development and Validation of the Rational and Intuitive Decision Styles Scale", Journal of Personality Assessment, 98 (2016), pp. 523-535.

[13] H.-Y. Kim, "Statistical notes for clinical researchers: assessing normal distribution (2) using skewness and

\subsection{Limitations}

Our sample size in this study was relatively small (91), which limited our choice of statistical techniques for our analysis. Nonetheless, this sample was collected from practitioners with significant experience with the EHR in different capacities. Such a sample is more difficult to access due to their limited availability and busy hours. Nonetheless, future studies can retest our model using other statistical techniques (e.g., CBSEM) with larger sample sizes.

kurtosis", Restorative dentistry \& endodontics, 38 (2013), pp. 52-54.

[14] H. J. Lanham, L. K. Leykum and R. R. McDaniel, "Same organization, same electronic health records (EHRs) system, different use: exploring the linkage between practice member communication patterns and EHR use patterns in an ambulatory care setting", Journal of the American Medical Informatics Association, 19 (2012), pp. 382-391.

[15] D. Levinthal and C. Rerup, "Crossing an apparent chasm: Bridging mindful and less-mindful perspectives on organizational learning", Organization Science (2006), pp. 502-513.

[16] X. Li, J. P.-A. Hsieh and A. Rai, "Motivational differences across post-acceptance information system usage behaviors: an investigation in the business intelligence systems context", Information Systems Research, 24 (2013), pp. 659-682.

[17] M. L. Markus and M. S. Silver, "A foundation for the study of IT effects: A new look at DeSanctis and Poole's concepts of structural features and spirit", Journal of the Association for Information Systems, 9 (2008), pp. 609632.

[18] L. S. Meyers, G. Gamst and A. J. Guarino, Applied multivariate research: Design and interpretation, Sage Publications, Inc, Thousand Oaks, CA., 2006.

[19] J. Nunnally, Psychometric Theory, McGraw-Hill, New York, 1978.

[20] W. J. Orlikowski, "The duality of technology: Rethinking the concept of technology in organizations", Organization Science (1992), pp. 398-427.

[21] J. Recker, Toward a design theory for green information systems, Hawaii International Conference on System Sciences (HICSS), Hawaii, 2016, pp. 44744483.

[22] V. L. Saga and R. W. Zmud, The nature and determinants of IT acceptance, routinization, and infusion, in L. Levine, ed., Diffusion, Transfer and Implementation of Information Technology, Elsevier Science Inc., Amsterdam, 1994, pp. 67-86.

[23] A. Slavitt, Comments of Centers for Medicare and Medicaid Services Acting Administrator, J.P. Morgan Annual Health Care Conference, https://blog.cms.gov/2016/01/12/comments-of-cmsacting-administrator-andy-slavitt-at-the-j-p-morganannual-health-care-conference-jan-11-2016/, 2016. 
[24] D. Straub, M.-C. Boudreau and D. Gefen, "Validation guidelines for IS positivist research", Communications of the Association for Information Systems, 13 (2004), pp. 380-427.

[25] D. M. Strong, S. A. Johnson, B. Tulu, J. Trudel, O. Volkoff, L. R. Pelletier, I. Bar-On and L. Garber, "A Theory of Organization-EHR Affordance Actualization", Journal of the Association for Information Systems, 15 (2014), pp. 53-85.

[26] J. Thatcher, R. Wright, H. Sun, T. Zagenczyk and R. Klein, "Mindfulness in Information Technology Use: Conceptual and Operational Definitions", MIS Quarterly, Forthcoming (2016).

[27] D. Vyas, C. M. Chisalita and A. Dix, "Organizational affordances: A structuration theory approach to affordances", Interacting with Computers, 29 (2017), pp. $117-131$.

\section{Appendix A. Measurement Instruments (Strongly Disagree - Strongly Agree)}

\section{Deep Structure Usage $\left(t_{2}\right)[25,26]$ :}

- I use features that help me capture and archive digital data about patients

- I use features that help me access and use patient information anytime from anywhere

- I use features that help me analyze patients' information.

- I use features that help me coordinate patient care across healthcare providers (e.g., different physicians and nurses)

- I use features that help me facilitate standardization of data, tasks, and roles among healthcare providers (e.g., different physicians and nurses)

- I use features that help me monitor healthcare operations and performance (e.g., audit trail of what was done, by whom, and when for the patient)

- I use features that help me facilitate substituting healthcare professionals for each other (e.g., shifting works across the same group of professionals, such as physicians)

- I use features that help me facilitate shifting work across different roles (e.g., shifting works across different groups of health professionals; for example, enabling nurses to do some of the physicians' tasks)

- I use features that help me incorporate rich information into clinical decision-making (e.g., providing medication alerts based on patient data, or providing pertaining tests which are needed for a specific diagnosis.)

\section{Innovative Use $\left(t_{2}\right)[16]$ :}

- I have discovered new uses of the EHR to enhance my work performance.

- I have used the EHR in novel ways to support my work.

- I have developed new applications based on the EHR to support my work.

- I have discovered new features of the EHR.

- I often experiment with new features of EHR system.

\section{Routine Use $\left(t_{2}\right)[16]$ :}

- My use of the EHR has been incorporated into my regular work practices.

- My use of the EHR is pretty much integrated as part of my normal work routine.

- My use of the EHR is now a normal part of my work.

\section{IT Mindfulness $\left(t_{1}\right)[26]$ :}

[Alertness to Distinction]

- I find it easy to create new and effective ways of using the EHR.

- I am very creative when using the EHR.

- I make many novel contributions to my work-related tasks through the use of the EHR.

[Awareness of Multiple Perspectives]

- I am often open to learning new ways of using the EHR.

- I have an open mind about new ways of using the EHR.

[Openness to Novelty]

- I like to investigate different ways of using the EHR.

- I am very curious about different ways of using the EHR.

- I like to figure out different ways of using the EHR.

[Orientation in the Present]

- I often notice how other people are using the EHR.

- I attend to the big picture of using the EHR.

- I get involved when using the EHR.

\section{Cognitive Absorption ( $\left.t_{1}\right)$ [5]:}

- When I was using the EHR, I felt totally immersed in what I was doing.

- When I was using the EHR, I did not get distracted easily.

- When I was using the EHR, I felt completely absorbed in what I was doing.

- When I was using the EHR, my attention did not get diverted very easily.

\section{Rational Decision Styles ( $\left.t_{1}\right)$ [12]:}

- I prefer to gather all the necessary information before committing to a decision.

- In decision-making, I take time to contemplate the pros/cons or risks/benefits of decision alternatives, before making a final choice.

- Investigating the facts is an important part of my decisionmaking process.

- I weigh a number of different factors when making decisions.

\section{Intuitive Decision Styles $\left(t_{1}\right)$ [12]:}

- When making decisions, I rely mainly on my gut feelings.

- I make decisions based on intuition.

- I rely on my first impressions when making decisions.

- I weigh feelings more than analysis in making decisions. 